\author{
吉名重多賀, 田中 昭 \\ 名城大学薬学部 ${ }^{2}$
Studies of Heterocyclic Compounds. IV.1) Ultraviolet Spectra of 2-(2-Furyl)vinylbenzenes and 2-(2-Furyl)vinylfurans \\ Shigetaka Yoshina and Akira Tanaka \\ Faculty of Pharmacy, Meijo University ${ }^{2)}$
}

(Received July 22, 1967)

\begin{abstract}
Ultraviolet spectra of 2-(2-furyl)vinylbenzenes and 2-(2-furyl)vinylfurans were measured, and relationship between the absorption maxima of these derivatives and the Hammett rule was examined. It was found that substituted 4-[2-(5-nitro-2-furyl)vinyl]benzenes, 2-(4-substituted phenyl)-3-(5-nitro-2-furyl)acrylic acids, and 2-substituted 5-[2-(5-nitro-2-furyl)vinyl]furans followed the Hammetts rule but not 2-(5-substituted 2-furyl)vinylbenzenes.
\end{abstract}

著者等は過去数回にわたって，2-(2-furyl)vinyl 誘導体の Wittig 反応による合成などについて報告し，前報》 においてはとくに 2-(2-furyl)vinylbenzene 類の合成ならびに抗菌力と半波還元電位との関係について検討を加 え, 今回さらにこれら誘導体の物理化学的性質と抗菌力との関連性を究明する目的で著者等の合成した 2-(2furyl)vinyl 誘導体すなわち, 2-(2-furyl)vinylbenzene 類および 2-(5-nitro-2-furyl)vinylfuran 類 (C) の約 40 種 ${ }^{4,5)}$ の化合物の紫外部吸收 (UV) スペクトルの湘定を行ない，それらの化学構造による共役性の遧い， $\lambda_{\max }$ と Hammett 則との関係ならびに $\lambda_{\max }$ と抗菌性との関連性などについて, 若干の検討を加えたのでそれについ て報告する.ささて本研究の関連文献》はは少なく西海枝等6)の 5-nitrofuryl polyene aldehyde 類ならびにその誘 導体の合成ならびにェチレン結合の增加による UV スペクトルの変化の報告は興味あるるのである.

TABlE I. $\lambda_{\max }$ of Ultraviolet Spectra

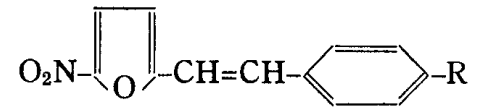

\begin{tabular}{|c|c|c|c|c|c|}
\hline $\mathbf{R}$ & $\lambda_{\max }$ & $\varepsilon_{\max }$ & $\mathrm{R}$ & $\lambda_{\max }$ & $\varepsilon_{\max }$ \\
\hline$-\mathrm{OH}$ & 412 & 8300 & \multirow[b]{2}{*}{$-\mathrm{NO}_{2}$} & $(470)$ & \multirow{2}{*}{$\begin{array}{r}(3800) \\
6600 \\
13800\end{array}$} \\
\hline & 284 & 29300 & & $\left\{\begin{array}{l}380 \\
275\end{array}\right.$ & \\
\hline$-\mathrm{CH}_{3}$ & $\begin{array}{l}390 \\
277\end{array}$ & $\begin{array}{l}12500 \\
18500\end{array}$ & \multirow{2}{*}{$\left(\mathrm{mp}{ }^{-\mathrm{CN}}\right.$} & $(406)$ & \multirow{2}{*}{$\begin{array}{l}(5000) \\
15000 \\
18000\end{array}$} \\
\hline$-\mathrm{H}$ & $\begin{array}{l}384 \\
275\end{array}$ & $\begin{array}{l}24500 \\
18600\end{array}$ & & $\begin{array}{l}374 \\
274\end{array}$ & \\
\hline$-\mathrm{Cl}$ & $\begin{array}{l}384 \\
278\end{array}$ & $\begin{array}{l}24500 \\
27000\end{array}$ & $\begin{array}{c}-\mathrm{CN} \\
\left(\mathrm{mp} 196-197^{\circ}\right)\end{array}$ & $\begin{array}{l}375 \\
278\end{array}$ & $\begin{array}{l}25500 \\
27500\end{array}$ \\
\hline
\end{tabular}

1）第 3 報： 薬誌, 88, (1968).

2) Location: Tenpaku-cho, Showa-ku, Nagoya.

3) 吉名重多賀, 田中 昭, 薬誌, 88, 398 (1968).

4) 吉名重多賀, 田中 昭, 山本勝美, 薬誌, 88, 65, (1968).

5) 吉名重多賀, 田中 昭, 家喜八郎, 薬誌, 88, 405 (1968).

6) H. Saikachi, H. Ogawa, J. Am. Chem. Soc., 80, 3642 (1958).

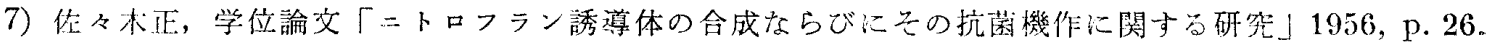


TABLE II. $\lambda_{\max }$ of Ultraviolet Spectra<smiles></smiles>

(B)

\begin{tabular}{|c|c|c|c|c|c|c|c|}
\hline $\mathrm{NO}_{2}$ & $\mathrm{R}$ & $\lambda_{\max }$ & $\varepsilon_{\max }$ & $\mathrm{NO}_{2}$ & $\mathrm{R}$ & $\lambda_{\max }$ & $\varepsilon_{\max }$ \\
\hline$o$ & $-\mathrm{CH}_{3}$ & $\left\{\begin{array}{l}310 \\
278\end{array}\right.$ & $\begin{array}{l}14900 \\
12200\end{array}$ & $m$ & $-\mathrm{CONH}_{2}$ & $\left\{\begin{array}{c}(352) \\
331\end{array}\right.$ & $\left\{\begin{array}{c}(23000) \\
34400\end{array}\right.$ \\
\hline$o$ & $-\mathrm{H}$ & $\begin{array}{l}301 \\
271\end{array}$ & $\begin{array}{l}26000 \\
26900\end{array}$ & $m$ & $-\mathrm{COOCH}_{3}$ & $\left\{\begin{array}{c}(347) \\
329\end{array}\right.$ & $\left\{\begin{array}{c}(12000) \\
17300\end{array}\right.$ \\
\hline$o$ & $\begin{array}{l}-\mathrm{CONH}_{2}(c i s) \\
\left(\mathrm{mp} 118-120^{\circ}\right)\end{array}$ & 288 & 17000 & $m$ & $-\mathrm{COOH}$ & $\left\{\begin{array}{c}(348) \\
327\end{array}\right.$ & $\left\{\begin{array}{c}(22400) \\
33800\end{array}\right.$ \\
\hline$o$ & $\begin{array}{l}-\mathrm{CONH}_{2}(\operatorname{trans}) \\
\left(\mathrm{mp} 195-196^{\circ}\right)\end{array}$ & $\left\{\begin{array}{c}(350) \\
314\end{array}\right.$ & $\left\{\begin{array}{c}(17000) \\
26000\end{array}\right.$ & $m$ & $-\mathrm{NO}_{2}$ & $\left\{\begin{array}{l}371 \\
265\end{array}\right.$ & $\left\{\begin{array}{c}(10200) \\
26300\end{array}\right.$ \\
\hline$o$ & $\begin{array}{l}-\mathrm{COOCH}_{3}(c i s) \\
\left(\mathrm{mp} 103-105^{\circ}\right)\end{array}$ & $\left\{\begin{array}{c}(300) \\
314\end{array}\right.$ & $\begin{array}{l}(9700) \\
13300\end{array}$ & $p$ & $\begin{array}{l}-\mathrm{CH}_{3} \\
\left(\mathrm{mp} 50-52^{\circ}\right)\end{array}$ & 270 & 35000 \\
\hline$o$ & $\begin{array}{l}-\mathrm{COOCH}_{3}(\operatorname{trans}) \\
\left(\mathrm{mp} \mathrm{116}-118^{\circ}\right)\end{array}$ & $\left\{\begin{array}{c}(350) \\
314\end{array}\right.$ & $\left\{\begin{array}{c}(18200) \\
27400\end{array}\right.$ & $p$ & $\begin{array}{l}-\mathrm{CH}_{3} \\
\left(\mathrm{mp} 110-111^{\circ}\right)\end{array}$ & $\begin{array}{l}383 \\
290\end{array}$ & $\left\{\begin{array}{l}24500 \\
29000\end{array}\right.$ \\
\hline$o$ & $\begin{array}{l}-\mathrm{COOH}(c i s) \\
\left(\mathrm{mp} 166-168^{\circ}\right)\end{array}$ & $\left\{\begin{array}{c}(350) \\
270\end{array}\right.$ & $\begin{array}{l}(6000) \\
19500\end{array}$ & $p$ & $-\mathrm{H}$ & $\begin{array}{l}368 \\
288\end{array}$ & $\begin{array}{l}26500 \\
24500\end{array}$ \\
\hline$o$ & $\begin{array}{l}-\mathrm{COOH}(\operatorname{trans}) \\
\left(\mathrm{mp} 207-208^{\circ}\right)\end{array}$ & $\left\{\begin{array}{c}(349) \\
315\end{array}\right.$ & $\left\{\begin{array}{c}(14500) \\
22500\end{array}\right.$ & $p$ & $-\mathrm{COOCH}_{3}$ & $\left\{\begin{array}{c}358 \\
(292)\end{array}\right.$ & $\begin{array}{l}33000 \\
(6600)\end{array}$ \\
\hline$o$ & $-\mathrm{NO}_{2}$ & $\left\{\begin{array}{c}369 \\
(262)\end{array}\right.$ & $\left\{\begin{array}{l}17500 \\
(23700)\end{array}\right.$ & $p$ & $-\mathrm{COOH}$ & $\begin{array}{l}374 \\
290\end{array}$ & $\left\{\begin{array}{l}29700 \\
10000\end{array}\right.$ \\
\hline$m$ & $-\mathrm{CH}_{3}$ & $\left\{\begin{array}{l}325 \\
(280)\end{array}\right.$ & $\left\{\begin{array}{c}39000 \\
(14700)\end{array}\right.$ & $p$ & $-\mathrm{NO}_{2}$ & $\left\{\begin{array}{c}(470) \\
380\end{array}\right.$ & $\left\{\begin{array}{c}(19000) \\
6600\end{array}\right.$ \\
\hline$m$ & $-\mathrm{H}$ & $\left\{\begin{array}{l}310 \\
271\end{array}\right.$ & $\left\{\begin{array}{l}48500 \\
33500\end{array}\right.$ & & & 275 & \\
\hline
\end{tabular}

TABLE III. $\lambda_{\max }$ of Ultraviolet Spectra

$\mathrm{O}_{2} \mathrm{~N}-\overbrace{\mathrm{O}}-\mathrm{CH}=\mathrm{CH}-\mathrm{O}_{\mathrm{O}}$

(C)

\begin{tabular}{|c|c|c|c|c|c|}
\hline $\mathrm{R}$ & $\lambda_{\max }$ & $\varepsilon_{\max }$ & $\mathbf{R}$ & $\lambda_{\max }$ & $\varepsilon_{\max }$ \\
\hline$-\mathrm{CH}_{3}$ & $\left\{\begin{array}{l}419 \\
300\end{array}\right.$ & $\begin{array}{r}25000 \\
1700\end{array}$ & $-\mathrm{CONH}_{2}$ & $\left\{\begin{array}{l}396 \\
302\end{array}\right.$ & $\begin{array}{l}24000 \\
17200\end{array}$ \\
\hline$-\mathrm{H}$ & $\left\{\begin{array}{l}403 \\
271\end{array}\right.$ & $\begin{array}{l}34000 \\
29000\end{array}$ & $-\mathrm{COOH}$ & $\left\{\begin{array}{l}392 \\
300\end{array}\right.$ & $\left\{\begin{array}{l}28000 \\
17000\end{array}\right.$ \\
\hline$-\mathrm{Br}$ & $\left\{\begin{array}{l}406 \\
300\end{array}\right.$ & $\begin{array}{l}25000 \\
17500\end{array}$ & $-\mathrm{NO}_{2}$ & $\left\{\begin{array}{c}(418) \\
400\end{array}\right.$ & $\left\{\begin{array}{c}(10000) \\
15000\end{array}\right.$ \\
\hline $\begin{array}{l}-\mathrm{COOCH}_{3} \\
\left(\mathrm{mp} 139-140^{\circ}\right)\end{array}$ & $\left\{\begin{array}{l}391 \\
290\end{array}\right.$ & $\begin{array}{l}25000 \\
16000\end{array}$ & & 275 & 5200 \\
\hline $\begin{array}{l}-\mathrm{COOCH}_{3} \\
\left(\mathrm{mp} \mathrm{189}-190^{\circ}\right)\end{array}$ & $\left\{\begin{array}{l}391 \\
298\end{array}\right.$ & $\begin{array}{l}25000 \\
16500\end{array}$ & & & \\
\hline
\end{tabular}

TABLE IV. $\lambda_{\max }$ of Ultraviolet Spectra

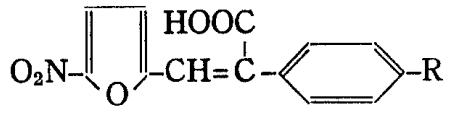

(D)

\begin{tabular}{|c|c|c|c|c|c|}
\hline $\mathrm{R}$ & $\lambda_{\max }$ & $\varepsilon_{\max }$ & $\mathrm{R}$ & $\lambda_{\max }$ & $\varepsilon_{\max }$ \\
\hline$-\mathrm{OCH}_{3}$ & $\left\{\begin{array}{l}360 \\
281\end{array}\right.$ & $\begin{array}{r}15600 \\
9000\end{array}$ & $-\mathrm{Cl}$ & $\begin{array}{l}355 \\
278\end{array}$ & $\begin{array}{r}21100 \\
9200\end{array}$ \\
\hline$-\mathrm{OCOCH}_{3}$ & $\left\{\begin{array}{l}363 \\
281\end{array}\right.$ & $\begin{array}{r}17000 \\
8600\end{array}$ & $-\mathrm{Br}$ & $\begin{array}{l}358 \\
282\end{array}$ & $\begin{array}{r}19000 \\
9600\end{array}$ \\
\hline$-\mathrm{NHCOCH}_{3}$ & $\left\{\begin{array}{l}360 \\
241\end{array}\right.$ & $\begin{array}{l}17000 \\
21100\end{array}$ & $-I$ & $\begin{array}{l}355 \\
231\end{array}$ & $\begin{array}{l}18000 \\
21200\end{array}$ \\
\hline$-\mathrm{H}$ & $\left\{\begin{array}{l}357 \\
279\end{array}\right.$ & $\begin{array}{r}16500 \\
9000\end{array}$ & $-\mathrm{NO}_{2}$ & $\begin{array}{l}353 \\
270\end{array}$ & $\begin{array}{l}18100 \\
14600\end{array}$ \\
\hline
\end{tabular}




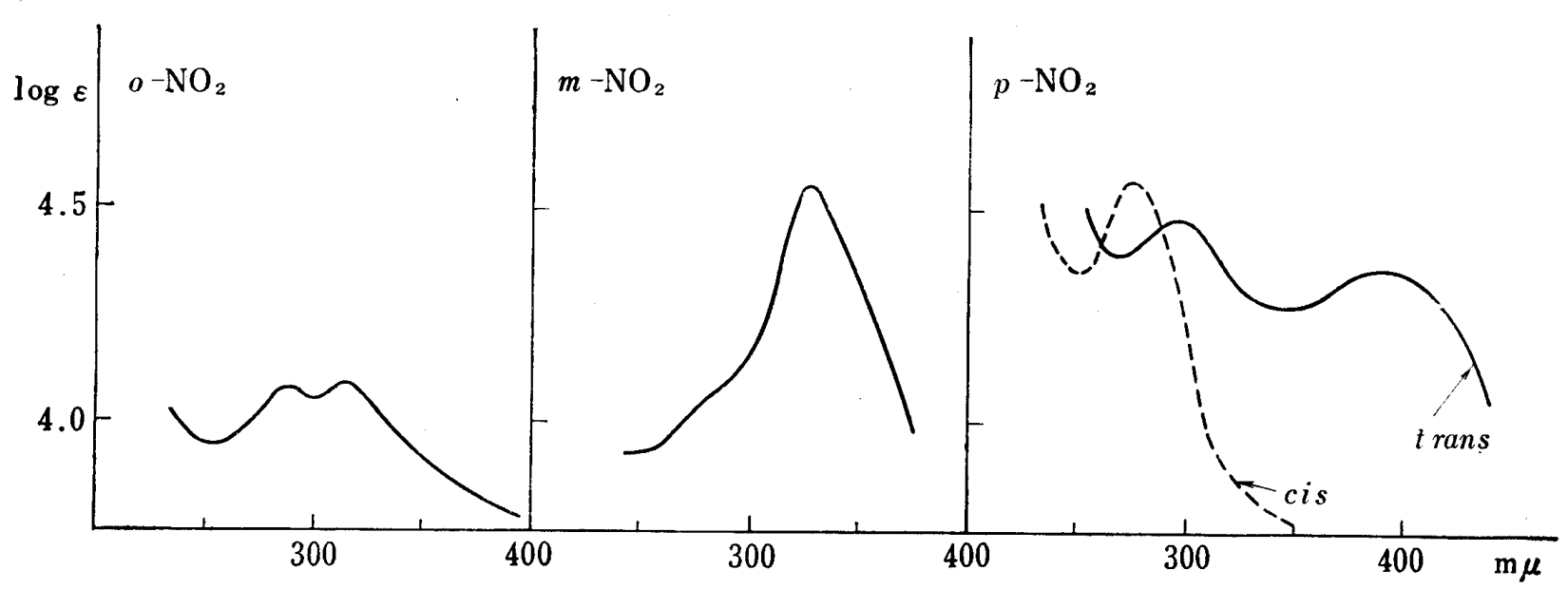

Fig. 1. Ultraviolet Absorption Spectra of 2-(5-Methyl-2-furyl)vinylnitrobenzenes<smiles></smiles>

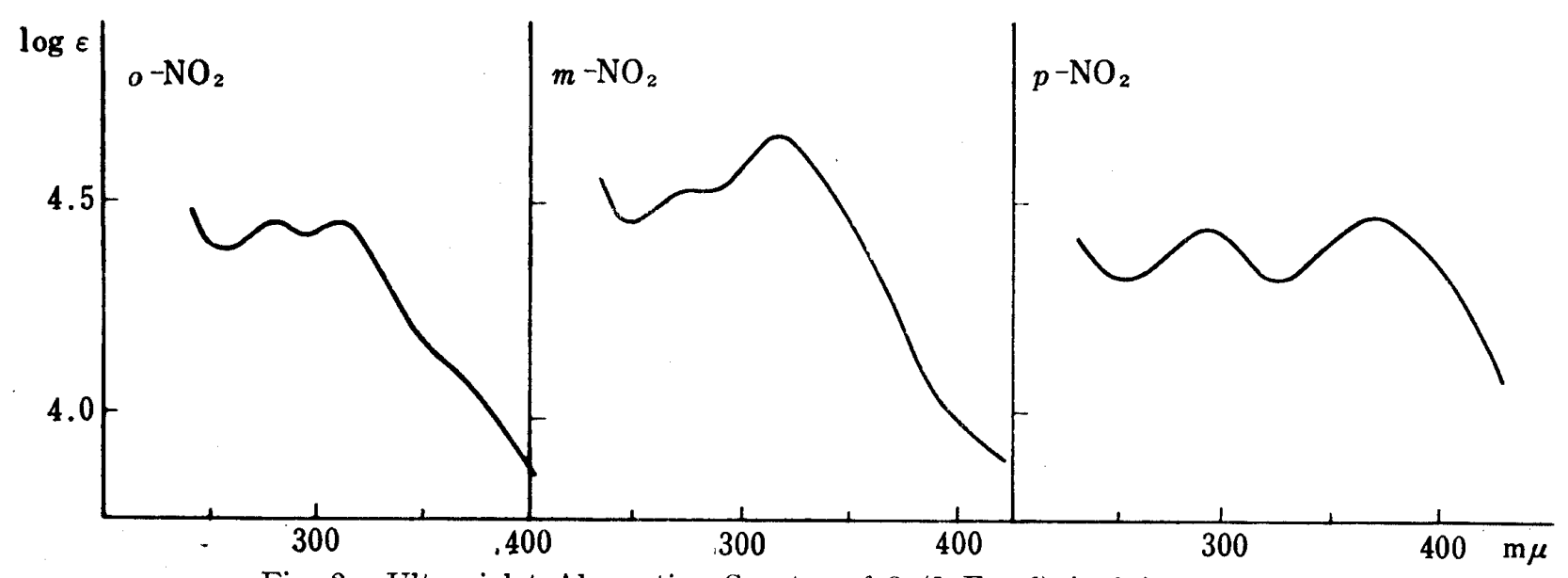

Fig. 2. Ultraviolet Absorption Spectra of 2-(2-Furyl)vinylnitrobenzenes<smiles>Cc1ccc(C=Cc2ccc([N+](=O)[O-])cc2)o1</smiles>
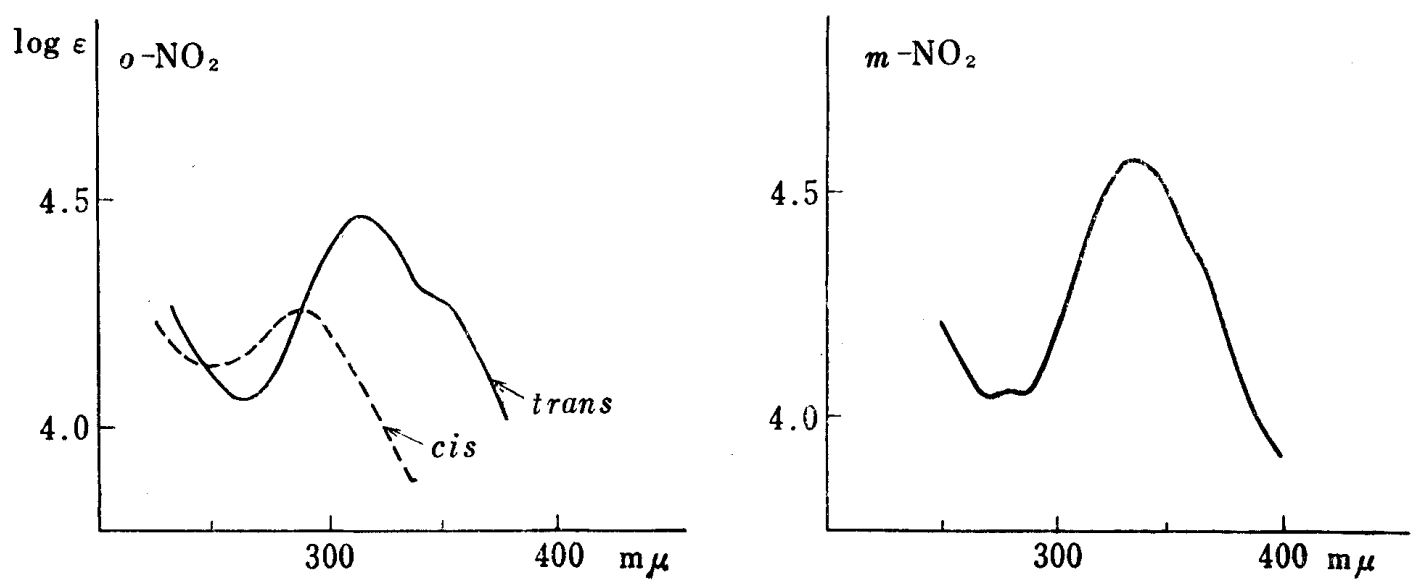

Fig. 3. Ultraviolet Absorption Spectra of 5-[2-(Nitrophenyl)vinyl $]-2-$ furancarboxamides<smiles>Cc1cc(C=Cc2ccc(C(N)=O)o2)ccc1[N+](=O)[O-]</smiles> 


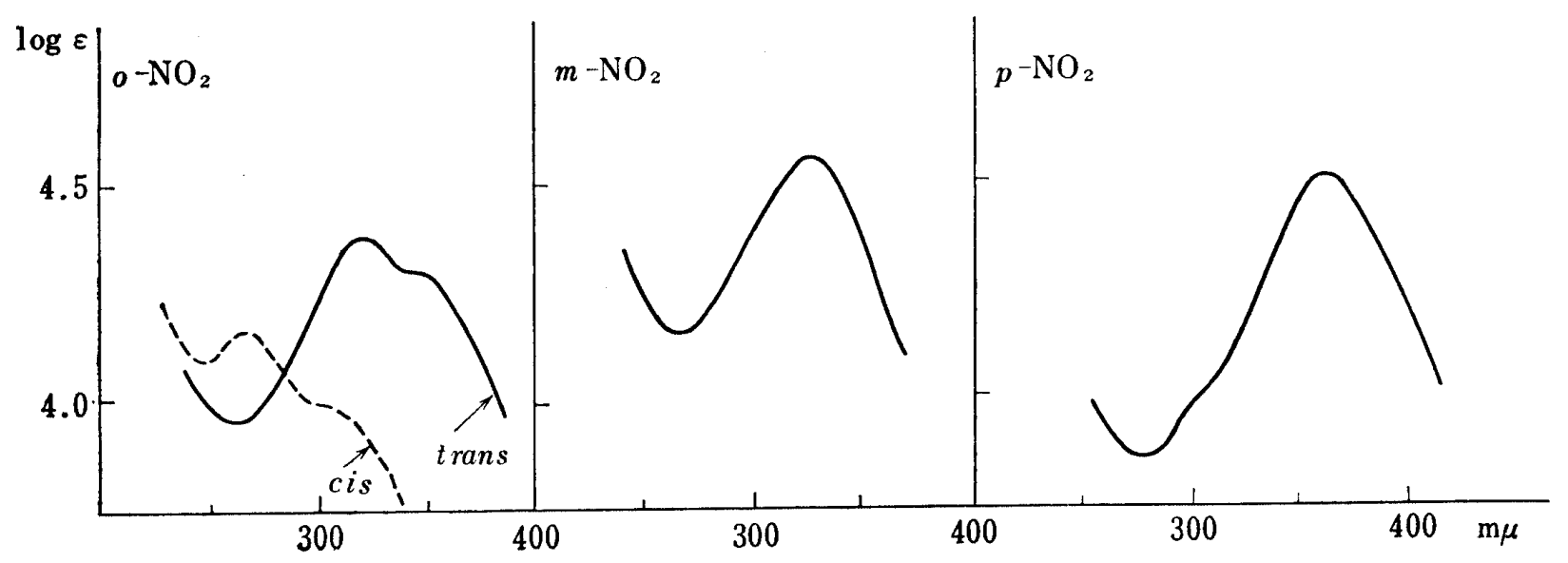

Fig. 4. Ultraviolet Absorption Spectra of Methyl 5-[2-(Nitrophenyl)vinyl]-2-furoates $\left(\mathrm{H}_{3} \mathrm{COOC}-\mathrm{O}_{\mathrm{O}}-\mathrm{CH}=\mathrm{CH}-X^{\mathrm{NO}_{2}}\right)$

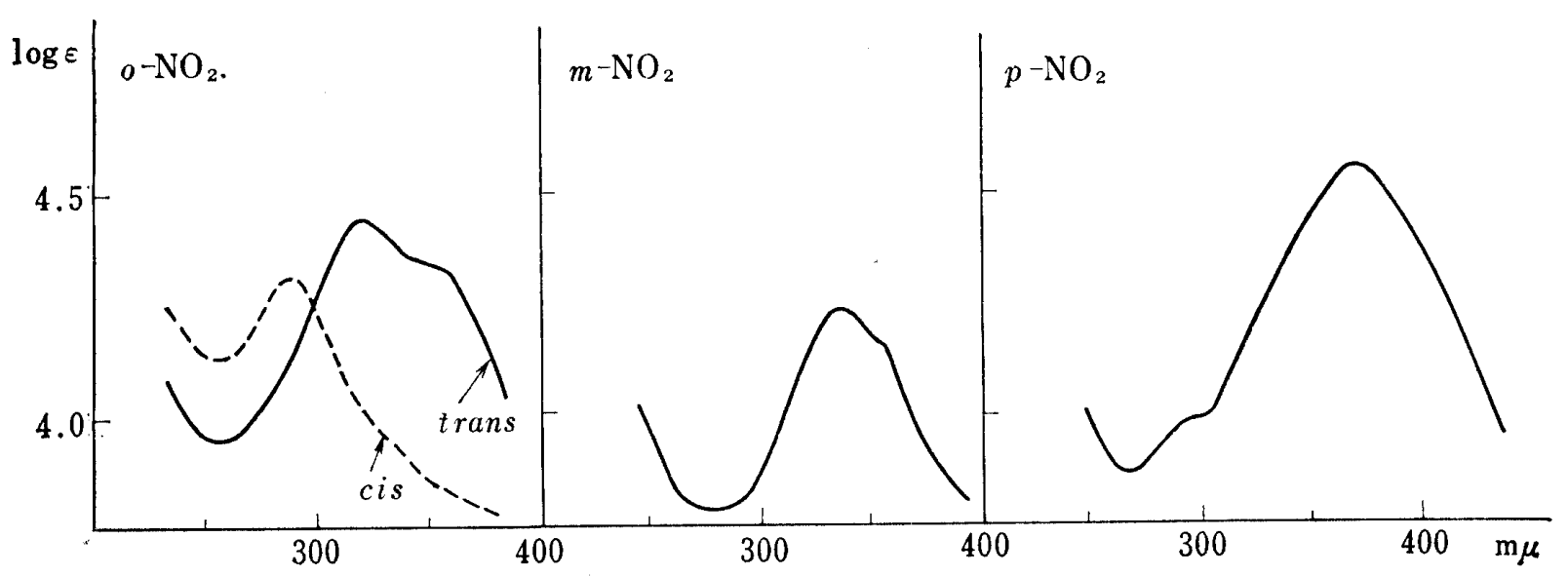

Fig. 5. Ultraviolet Absorption Spectra of 5-[2-(Nitrophenyl)vinyl]-2-furoic Acids<smiles>O=C(O)c1ccc(C=Cc2ccc([N+](=O)[O-])cc2)o1</smiles>

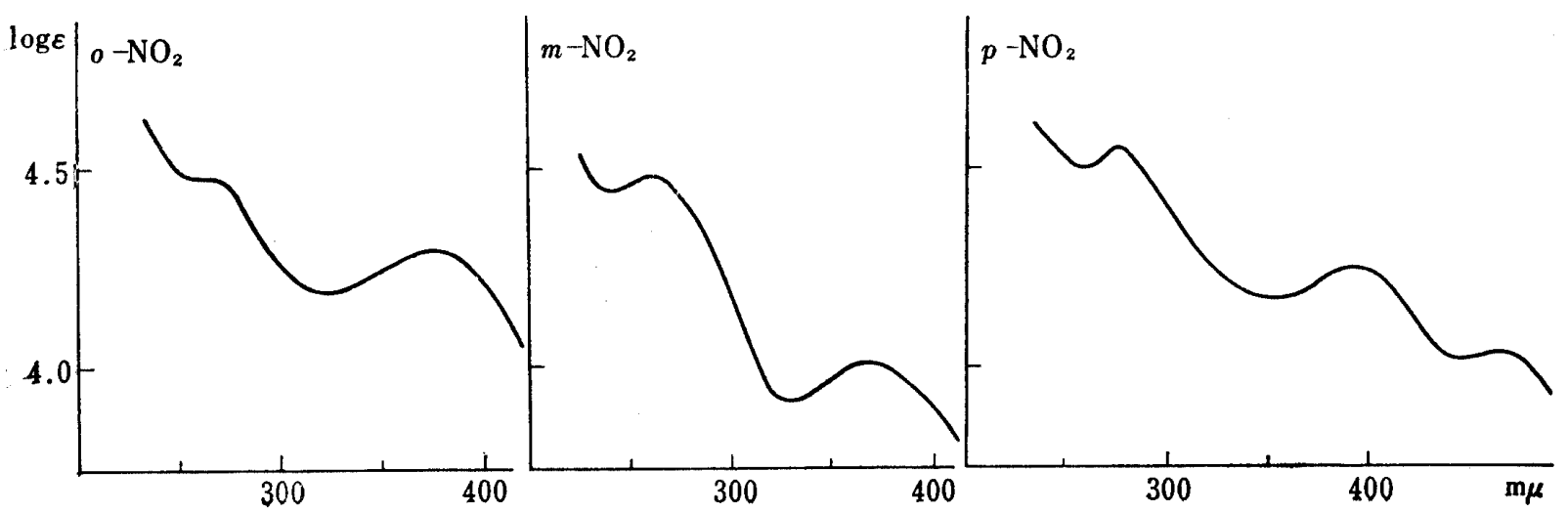

Fig. 6. Ultraviolet Absorption Spectra of 2-(5-Nitro-2-furyl)vinylnitrobenzenes<smiles>O=[N+]([O-])c1ccc(/C=C/c2ccc([N+](=O)[O-])o2)cc1</smiles> 

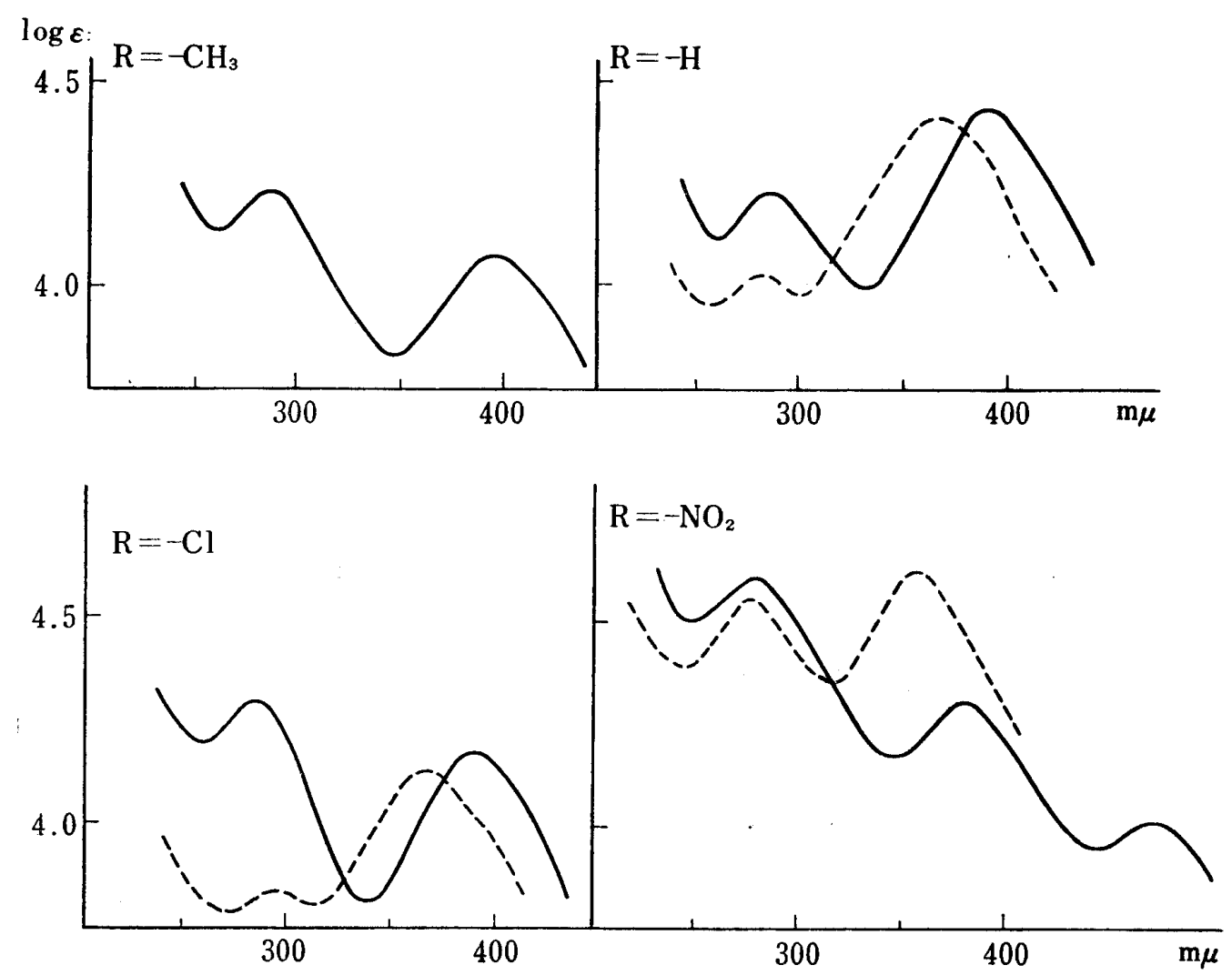

Fig. 7. Ultraviolet Absorption Spectra of 4-[2--(5-Nitro-2-furyl)vinyl $]$ benzenes<smiles>[R]c1ccc(C=Cc2ccc([N+](=O)[O-])o2)cc1</smiles>

Dotted line: $\mathrm{O}_{2} \mathrm{~N}-\left\|_{\mathrm{O}}\right\|_{-\mathrm{CH}=\mathrm{C}-}^{\mathrm{HOOC}} \longrightarrow-\mathrm{R}$

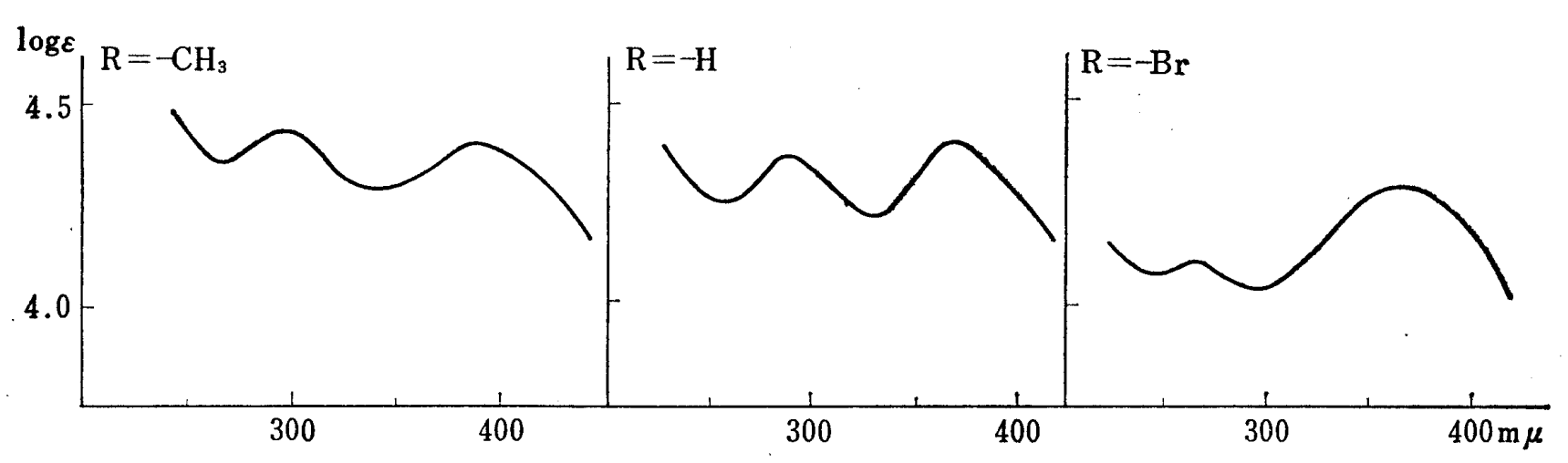

Fig. 8. Ultraviolet Absorption Spectra of 4-[2-(5-Substituted-2-furyl)vinyl]nitrobenzenes $\left(\mathrm{R}-\|_{\mathrm{O}} \mathrm{CH}=\mathrm{CH}-\longrightarrow-\mathrm{NO}_{2}\right)$ 


\section{$\log \varepsilon$}
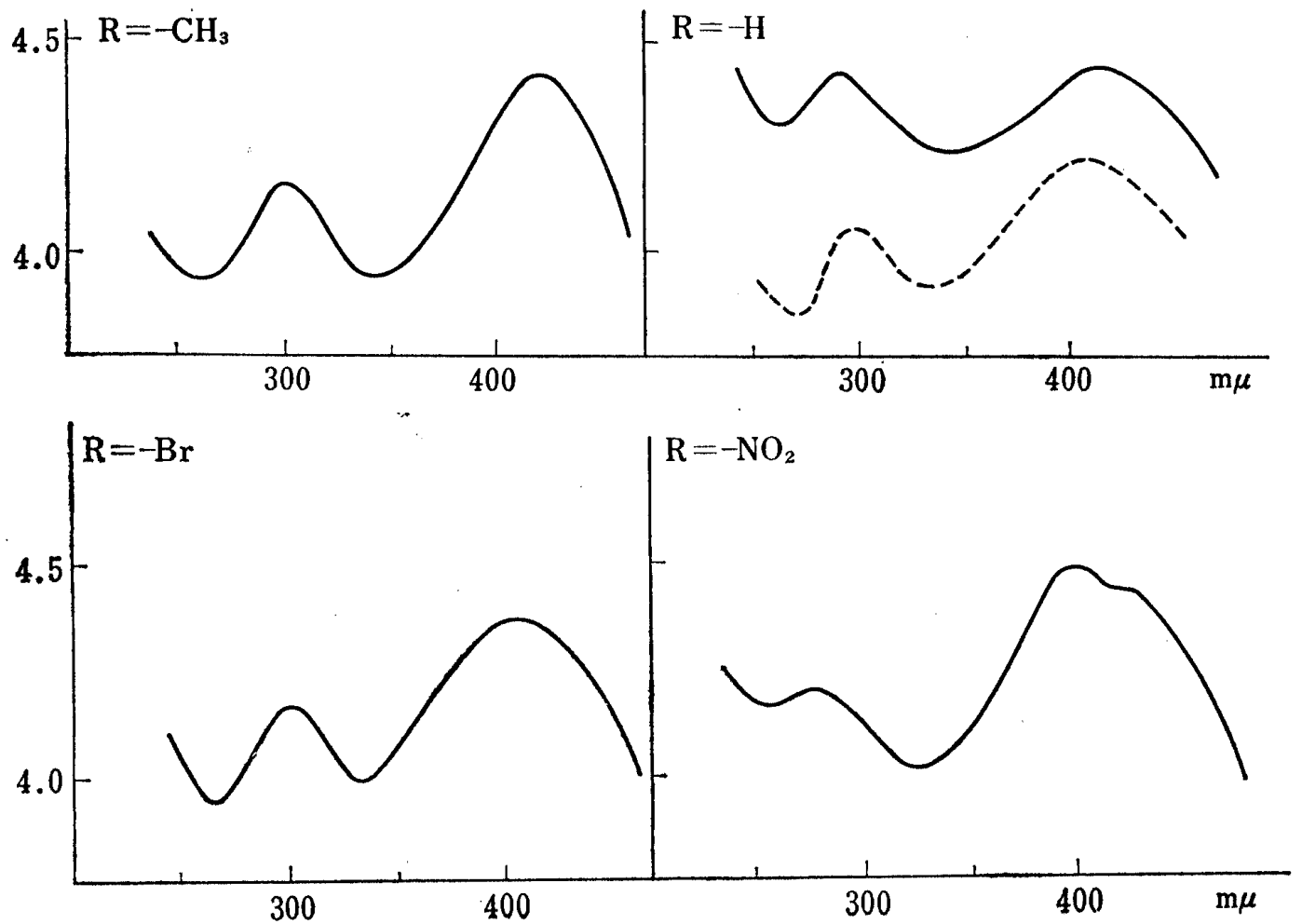

Fig. 9. Ultraviolet Absorption Spectra of 2-Substituted-5-[2-(5-nitro-2-furyl)vinyl]furan

$$
\text { Dotted line: }\left(\mathrm{O}_{2} \mathrm{~N}-\mathrm{O}_{\mathrm{O}}, \begin{array}{c}
\mathrm{HOOC} \\
\mathrm{O}
\end{array}\right.
$$

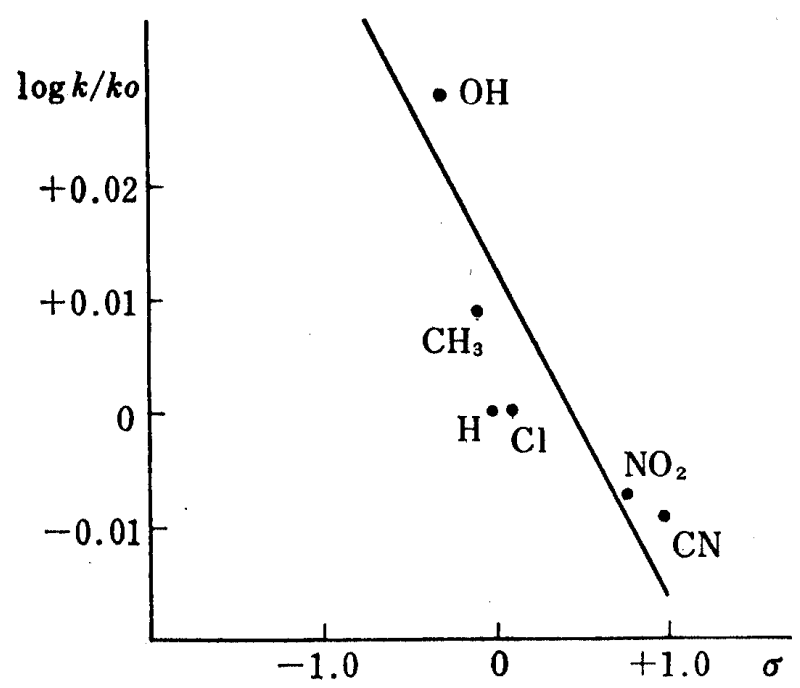

Fig. 10. Hammett's Rule Graph of

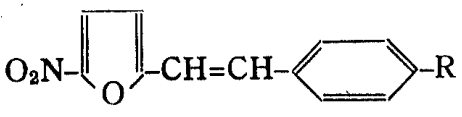

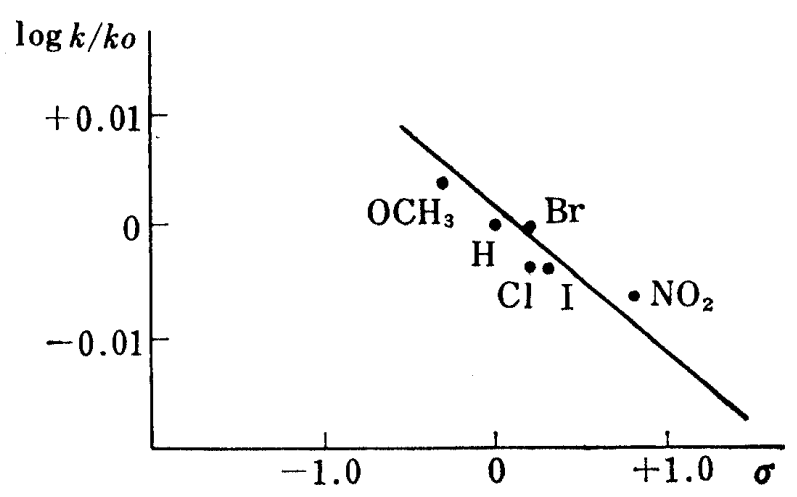

Fig. 11. Hammett's Rule Graph of

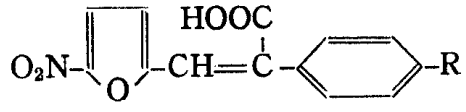

(D)

\section{実験 の 部}

UV スベクトルの測定 $10^{-4}-10^{-5} モ ル$ 濃度ェタノール溶液で日本分光 UV-75（自記）を使用して測定した. その結果は Table I, II, III 招上び IV であり，また，図示すれば Fig. 1-10のようである. 


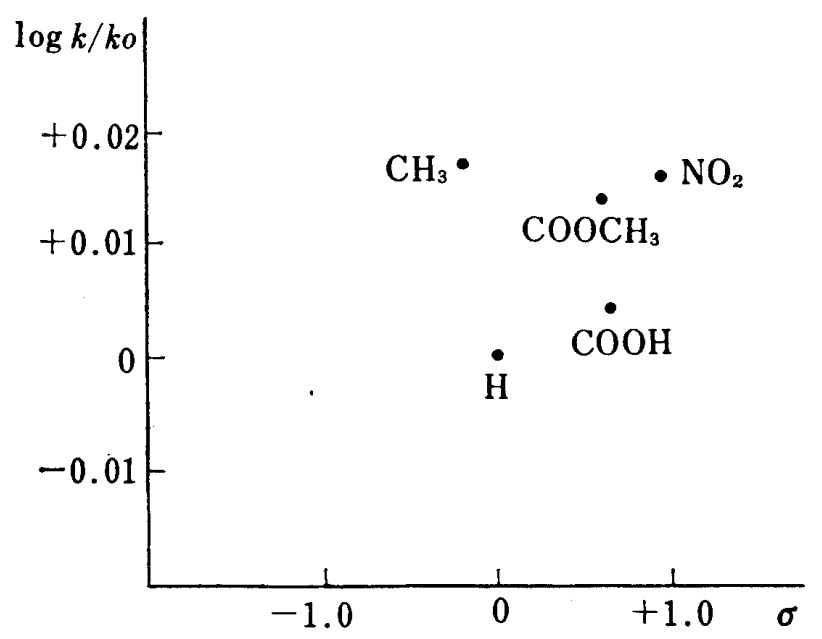

Fig. 12. Hammett's Rule Graph of

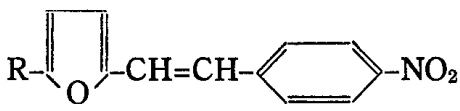

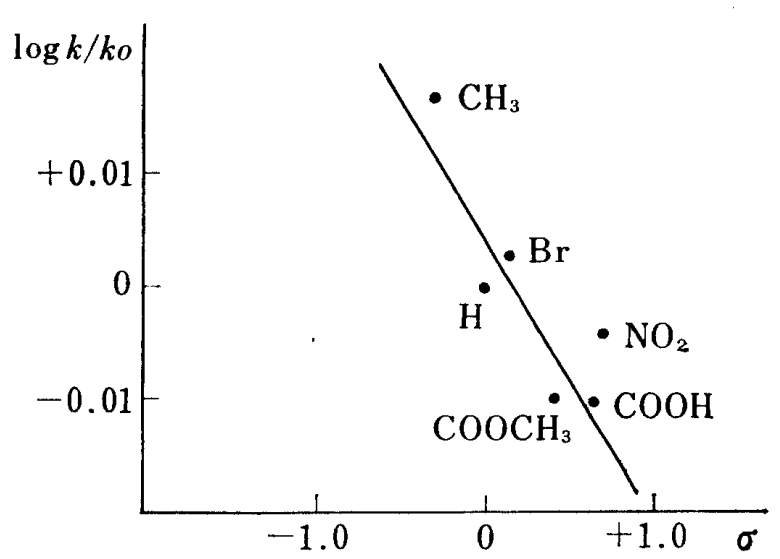

Fig. 13. Hammett's Rule Graph of<smiles></smiles>

\section{考}

察

1) $\lambda_{\max }$ と化学螣造との関係 a. 2-(5-Nitro-2-furyl)vinylbenzene 類 (A) (Table I, Fig. 6 执よび Fig. 7) の $\lambda_{\max }$ は全般的に対応する 2-(p-nitrophenyl)viny furan 類(B) (Table II 扣よび Fig. 8) のそれよりも長波長 域にあり，フラン核上 5-位ニト口基の共役系に及ぼす影響が大である.

b. (A) と 2-(5-nitro-2-furyl)vinylfuran類 (C) (Table III 抒よび Fig. 9) との $\lambda_{\max }$ を比較するとCのそれは Aのそれよりもさらに長波長域にあった。

c. 2-(5-Substituted-2-furyl)vinyl nitrobenzene 類 (B) (Table II および Fig. 1-8) のベンゼン核上ニトロ 基の置換位置の違いにより， $\lambda_{\max }$ 值は $0<m<p$ の順に長波長域に移行する傾向がある.

d. (A) と 2-(4-substituted-phenyl)-3-(5-nitro-2-furyl)acrylic acid ${ }^{8}$ (D) (Table IV) との $\lambda_{\max }$ を比較する に(A)のそれは長波長側にあった.

以上の結果から，フラン核 5-位の置換基が共役系に及汸す影響は対応するベンゼン核置換基のそれよりもかな り大きいことが推察される。また，興味あることには A のエチレン結合のベンゼン核側の炭素の水素の 1 個を -COOH に置換した (D) ではベンゼン核とフラン核との共役性は若干阻害されるものと思われる.

2) $\lambda_{\max }$ と Hammett's rule 以上测定により得られた $\lambda_{\max }$ 值と置換基との関係が Hammett's rule の log $K / K_{0}=\rho \bullet \sigma$ の式にしたがうかを検討したところ，Fig. 10，11，12 および 13 のようであった.すなわち $\mathrm{A}$ ， C 括よび D は值線関係が成り立ら，一方 B では直線関係が認められなかった。

3) $\lambda_{\max }$ と抗菌性 過去数回にわたって種々 2-furyl-vinyl 型化合物の合成とその抗菌性を報告3-5,9) した が，それら抗菌性の結果と今回測定した $\lambda_{\max }$ との関係を総合判断すると全般的に，この種化合物では $\lambda_{\max } か ゙$ $370 \mathrm{~m} \mu$ 前後または，それより長波長域にあるものに抗菌性の強いものが多く見られる．例えば 5-[2-(5-nitro2-furyl)vinyl]furan 類 (C) としては methyl 5-[2-(5-nitro-2-furyl)vinyl]-2-furoate $\left(\lambda_{\max }\right.$ : $\left.391 \mathrm{~m} \mu\right), 2-\mathrm{car}-$ bamoyl-5-[2-(5-nitro-2-furyl)vinyl]furan $\left(\lambda_{\max }\right.$ : $\left.396 \mathrm{~m} \mu\right), 2-(5$-nitro-2-furyl)vinylbenzene 類 (A および B) としては 4-[2-(5-nitro-2-furyl)vinyl]cyanobenzene $\left(\lambda_{\max }: 375 \mathrm{~m} \mu\right), 2-[2-(5$-nitro-2-furyl) vinyl]nitrobenzene $\left(\lambda_{\max }: 369 \mathrm{~m} \mu\right), 3-\left[2-(5-n i t r o-2-f u r y l)\right.$ vinyl]nitrobenzene $\left(\lambda_{\max }: 371 \mathrm{~m} \mu\right)$ およよび 4-[2-(5-nitro-2-furyl)vinyl]nitrobenzene $\left(\lambda_{\max }: 380 \mathrm{~m} \mu\right)$ などをあげることができる.

4) $\lambda_{\max }$ の Hammett's rule の $\log K / K_{0}$ 值と抗菌性 Fig. 10，11 および 13 のような関係の成立する化 合物は概して $\log K / K_{0}<0$ のものに抗菌性の強いものが多い.

8) 西海枝東雄, 田中明, 薬誌, 81, 1513 (1961).

9) 日本薬学会第86年年会発表, 富山，1966年 4 月。 